\title{
Stereospecific access to $\alpha$-hydroxycarboxylic acids: chiral pool approach using arabinose and galactose. Preliminary results.
}

\author{
Paulo Roberto da Silva, Fábio da Paixão Soares, Bogdan Doboszewski
}

Departamento de Química, Universidade Federal Rural de Pernambuco, 52171-900 Recife, PE, Brasil *bdoboszewski@hotmail.com

Keywords: chiral pool, $\alpha$-hydroxycarboxylic acids, stereospecific

\section{INTRODUCTION}

Carbohydrates are well-known substrates for stereoselective chiral pool synthesis, due to their known absolute configurations and developed methodology of selective manipulation of the $-\mathrm{OH}$ groups. Since both enantiomeric final products are sometimes necessary, D- and L- sugars should be available. Since D- and L-arabinose are easily available, we concentrated attention on them to obtain general building blocks for $\alpha$ hydroxycarboxylic acids synthesis. Alternatively, Dgalactose was used considering a fact, that it can be converted to its L-enantiomer. Consequently, both approaches are stereospecific.

\section{RESULTS AND DISCUSSION}

Logic of chirality utilization throughout the present work is shown in the Picture 1.

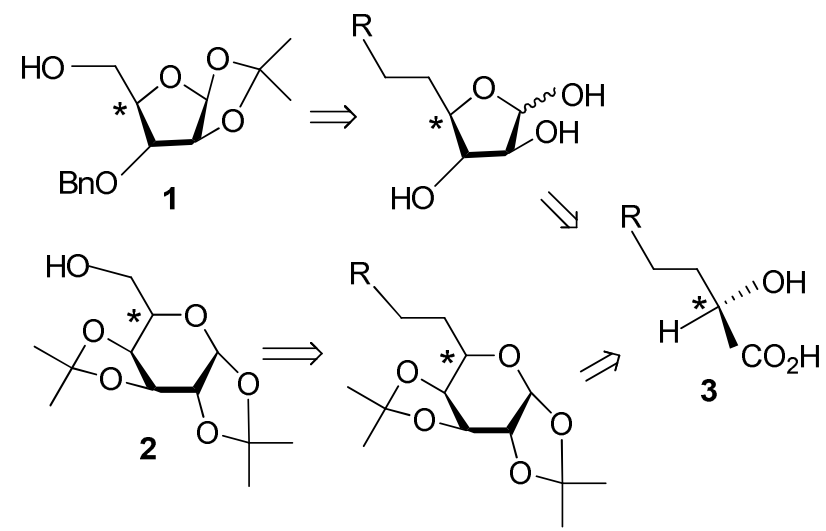

Picture 1. Utilization of chirality of the C4 and C5 atoms in 1 and 2, respectively, to get $\alpha$-hydoxycarboxylic acids.

D-Arabinose was converted to its derivative $\mathbf{1}$ and further worked-out as shown in the Scheme 1 to get a critical intermediate 4 , which will be used to obtain 5 and eventually the targets 3 . It should be pointed out that repetition of the same scheme using Larabinose will allow obtention of the enantiomeric targets, and in fact we already have an enantiomer of 1 derived from L-Ara.

An alternative approach to 3 is to use Dgalactopyranose $\mathbf{2}$ as shown in the Scheme 2.
Apparently simple substitution at the primary position in 2 is troublesome. Using the best leaving group, a trifluorosulfonate, smooth substitution with sodiomalonate was realized to get $\mathbf{6}$. The structure of this compound was confirmed by X-ray. ${ }^{1}$ Alkylations at the acidic $C$ atom in 4 and 6 are in progress.
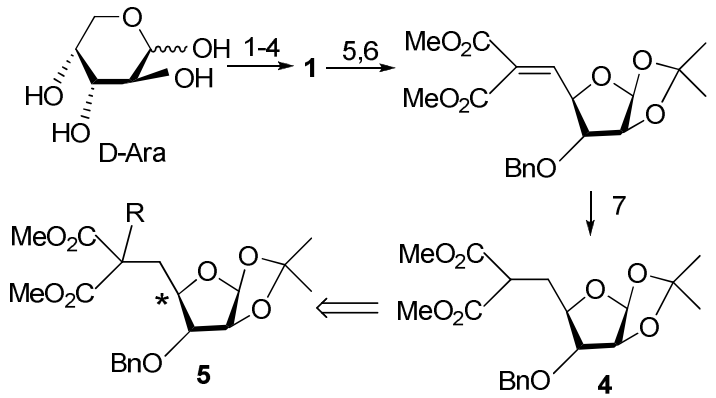

Conditions: 1. $\mathrm{tBuPh}_{2} \mathrm{SiCl}$, imidazole, $58 \%$; 2. acetone, $\mathrm{H}_{2} \mathrm{SO}_{4}, 67 \%$ 3. $\mathrm{BnBr}, \mathrm{PTC}, 83 \% ; 4 . \mathrm{Bu}_{4} \mathrm{NF}, 72 \% ; 5 . \mathrm{NaNO}_{2}, \mathrm{Ac}_{2} \mathrm{O}$ 6. $\mathrm{CH}_{2}\left(\mathrm{CO}_{2} \mathrm{Me}\right), \mathrm{MeO}^{-} \mathrm{Na}^{+}, 55 \%$ two steps; $7 . \mathrm{NaBH} 4,71 \%$

Scheme 1. Synthesis of the intermediate 4 starting from $\mathrm{D}$-arabinose.

$$
\begin{gathered}
2 \underset{\text { 1. } \mathrm{Tf}_{2} \mathrm{O}, \mathrm{Py}}{\mathrm{NaH}, \mathrm{CH}_{2}\left(\mathrm{CO}_{2} \mathrm{Et}\right)_{2}} \\
\text { 82\% for two steps }
\end{gathered}
$$

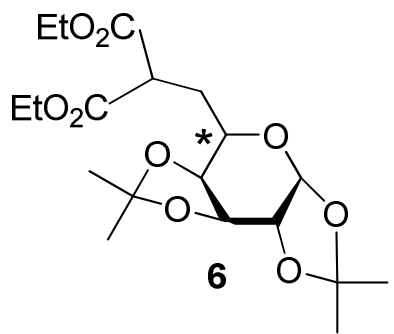

Scheme 2. Synthesis of the intermediate 6 via substitution at the $\mathrm{C} 6$ of D-galactopyranose.

\section{CONCLUSION}

D-Arabinofuranose and D-galactopyranose were functionalized to get the intermediates for $\alpha$ hydroxycarboxylic acids synthesis.

\section{REFERENCES}

Doboszewski, B.; Silva, P.R. da; Nazarenko, A.Y.; Nemykin, V.N. Acta Cryst.2010,E66,3217 